\title{
12
}

\section{IMPLICATIONS AND PERSPECTIVES FOR EXPERIMENTAL MUSEOLOGY}

\author{
Kirsten Drotner, Michael Haldrup, and Marianne Achiam
}

As this volume demonstrates, experimental museology is about change. This is because experimentation by definition involves pushing boundaries, questioning institutional roles, routines and transgressing familiar ways of doing things. In that sense, experimentation is not limited to one dimension of the museum and its modes of communication. Experimental processes may focus on theoretical or practical dimensions, and they can evolve at different scales, from tweaking existing modes of collaboration to transforming organisational strategies. Experimental processes may also be set in motion by different agents related to museology, such as researchers, museum leaders or professionals or museum audiences. Moreover, experimental processes may be intended to serve different purposes, catalysing incremental or radical change. Yet, for all of these aspects experimental museology illuminates fundamental contingencies. Intended and actual practices, priorities and purposes do not always add up, and change processes materialise within structural dilemmas beyond the immediate remits of museums, as we uncovered in the volume introduction.

The preceding chapters offer a range of captivating examples of how to navigate these contingencies with regard to museum institutions, modes of representation and user engagement. Taken together, the chapters document how many museums deal with change by challenging received notions of their relations to the world around them. They move towards more contextualised, critical and communicative positions; and, as we argued in our introduction, museology needs to follow suit and, at best, catalyse these processes by adopting more holistic approaches to theory and practice.

Cutting across individual chapters, three implications stand out as particularly pertinent when navigating these contingencies through holistic approaches. There are ethical implications when museum institutions explore new and dynamic forms of collaboration; there are implications with regard to diversity when 
museums design novel modes of communication; and democratic implications when museums engage with communities holding divergent affinities and values. So, here we chart key insights about these implications across the volume to help identify principles and suggest guidelines for successful change processes when museums enter uncharted territories of experimentation.

\section{Handling ethics in dynamic processes of collaboration}

Concern for ethical issues is not new to museums, and all museums joining ICOM must subscribe to its global code of ethics as a binding guideline of professional practice. Yet, a corollary of socio-technical changes, as outlined in the introduction, has sparked a reappraisal of what Janet Marstine calls the 'moral agency' of museum institutions (Marstine, 2011, p. 5). This focus moves ethical considerations away from general codes and guidelines for individual museum professionals and on to specific institutional practices of what the museum 'does with its resources, and for whom' (Marstine, 2011, p. 8).

Such considerations are particularly pertinent when museums explore experimental approaches that will often involve the formation or expansion of new partnerships, from design companies and leisure industries on to NGOs, local community groups and wider global social and cultural networks and interests. Some of these partners may sign formal contracts with a particular museum as a basis of collaboration. Other partners' operations may not be defined by legally binding regulations and rules of governance. This will often be the case for local community groups and online networks whose members, rather than having clearly demarcated common interests and identities, are bound by 'weak ties' (Granovetter, 1983) and rarely have the resources of rights claiming should their autonomy, integrity or privacy be challenged during collaboration with a museum. Such challenges are particularly pertinent when experimentation involves the generation of digital data because museums have only recently begun to address the ethical issues involved in datafication and corporate platformisation (Pruulmann-Vengerfeldt \& zu Hörste, 2020).

Processes of experimentation and exploration are most successful when they are practised on a basis of equity and trust, because all parties involved enter uncharted territory in a physical and mental sense. Yet, the structural conditions of such processes often rest on inequities of power with museums having the upper hand. The possibility of conflicts between processes and their foundations put extra ethical demands on the museum to act with due diligence, including exerting public accountability about the processes, the choices made along the way and the outcomes.

This volume provides a number of illustrations of how ethical dilemmas are handled. For example, Haitham Eid, in Chapter 8, stresses that public admittance of experimentation failures is actually a major means for museums to build public trust, because it affirms values of transparency and fairness. Similarly, the contribution by Jennifer Carter and Christina Lleras, in Chapter 3, shows what 
happens when 'process becomes praxis' and they explore how museums may benefit when their staff engages in continuous reconsiderations of the conceptual foundations and framework of their museum in addressing a contentious past. By providing audiences with a narrative of Columbia's armed conflict that revealed the structural dimensions of the conflict while also encouraging deeper personal introspection and interpretive responsibility in terms of the conflict, the museum offered its audiences a different kind of understanding, and it became responsive to public dialogues on the evolving peace process. A similar ambition is clearly at stake in Erika Grasso's and Gianluigi Mangiapane's contribution, in Chapter 4, on how a museum institution reflects on collections as bearers of critical memories and unfair relations between cultures as an opportunity to enhance social inclusion. Finally, Anne Scott Sørensen, in Chapter 11, demonstrates how the continuous involvement of young people in developing museum initiatives through continuous participation, evaluation and feedback not only increases their ownership and representation, it also adds to the multi-vocality of researchers, surveyrespondents, activists and visitors who both reinforce and challenge each other, thus shaping a joint engagement with burning questions and a will to change.

The ethical implications of museum experimentation call on museums to actively promote principles of ethical interaction with the outside world. Such principles should go beyond general statements of accountability and be specific principles that can guide practice. An obvious first start is to learn from existing work, for example in qualitative research and citizen science (Rasmussen \& Cooper, 2019; Miller et al., 2012), and draft written procedures, or letters of understanding, when partnering with local communities, underserved groups or NGOs. Such procedures should, as a minimum, spell out all participants' basic rights and responsibilities, including informed consent on data generation, storage and use, decision-making procedures and copyright to results, accurate expectations for participation, means of protection, possible remuneration and resolution of conflicts.

\section{Developing diversity of communication}

Museums experiment for different reasons. Some may act on political priorities to demonstrate potential of public innovation; some may wish to challenge their own received notions of proper museum work; and others may seek adjustment to changed financial, political or technological circumstances through reimagining their interactions with the outside world. Whatever the reasons, much museum experimentation focusses on developing a greater diversity of communication than museums have done before. Underpinning these developments is a widening recognition that museums are not neutral institutions and impartial spaces of representation. Museums are always enmeshed in socio-cultural, economic and political processes, which may not be of museums' own making but which nevertheless colour their worldview and range of actions. European museums, with a long tradition of public funding and ideals of public good, operate under 
very different conditions from museums in regions with more recent, or more restrictive, notions of public good and equitable access; and museums in the U.S.A., in their turn, are more dependent on corporate and private sponsorships and individual visitor satisfaction. While macro-level ramifications of museums differ markedly, their micro-level effects are that museums around the world attend to their surroundings as rarely before; and they increasingly realise that one size of communication does not fit all. Importantly, this focus on communicative diversity does not merely involve an incremental widening of existing tools providing spectacular exhibitions on popular themes or launching flashy and userfriendly websites. Experimenting to capture a greater communicative diversity basically involves more radical forms of innovation where new communicative tools are applied and where existing tools are combined in unfamiliar ways. Importantly, such experiments equally reshuffle taken-for-granted perceptions and professional knowledge claims, because communication is always about something for somebody. So, experimenting to reach wider and more diverse audiences fundamentally serves to defamiliarise substance as much as forms of communication.

This volume offers several illustrations of such radical experiments. For example, Line Nicolaisen, Marianne Achiam and Tina Ibsen, in Chapter 10, stress how established notions of astrophysics and its implied audiences are questioned and transformed when designing for a gender-inclusive exhibition which departs from joint modes of interaction. Similarly, Sarah Kenderdine, in her Chapter 1 turns the hidden power of commodified datafication on its head and shows how museums can experiment with interactive, multimodal designs that visualise and embody data as material representations. She stresses how these material modes of meaning-making help shift the power back to audiences and away from mostly commercial platform data providers.

Furthermore, Rodrigo Tisi Paredes, in Chapter 2, illuminates how the deliberative visualisation and materialisation of 'impossible objects' in immersive environments is used as a means of having citizens' connect with otherwise invisible and intangible heritage and thus increase accessibility. Another strategy is employed in the case unravelled by Mieke Bal, in Chapter 6, discussing the use of shock as a deliberate attempt to push audiences out of a consumerist attitude. By slowing down visitors, mixing media and creating 'temporal turbulence' in the use of chronology traditional modes of representation are shaken so that museum visitors are activated to think for themselves in order to bring art to live in the museum.

As these examples indicate, experimentation to achieve more diverse modes of communication works best when the museum has the foresight to set down and follow certain principles of operation. Importantly, these principles must encompass and align internal as well as external means of communication. Internally, staff members involved with communication design must acknowledge and follow priorities in terms of thematic focus, technical affordances and audience address. Externally, similar principles need to be evident to audiences, for example with 
regard to the professional choices made about selecting certain themes and angles rather than others. Illuminating such principles is an important pathway to advance the relevance of museum experimentation to museum audiences.

\section{Promoting cultural citizenship}

For, at the end of the day, experimental museology is of fundamental importance not because it helps innovate museum organisations or museum output, but because it helps museums in developing actual and potential audiences' knowledge resources as means of action. As several chapters in this volume illustrate, museum experimentation often involves audience groups as co-developers and codesigners. Such involvement is a way of testing whether new approaches and solutions work well with actual and potential audiences. But, more importantly, it is a means for the museum to apply people's everyday experiences, affinities and values as resources of change and to rethink how the museum can help strengthen such resources.

So, an important implication of experimental museology is that museums are invited to reconsider whether their work ultimately promotes private gain or public value, as described in the introduction to this volume. Working to sustain citizen empowerment as a public value is fundamental to democratic processes. Hence, experimental museology offers a key inroad to develop and sustain cultural citizenship.

Traditionally, the notion of citizenship is associated with universal political rights to be acquired (and often fought for); or, it is associated with individual affinities and identifications with particular communities. What chapters in this volume clearly illustrate is that culture is key to the formation of citizenship. This is because cultural processes and practices within and beyond cultural institutions are fundamental training grounds for democracy (Dahlgren, 2006; Isin \& Nielsen, 2002). As we have seen through this volume, involving groups of actual and potential audiences in museum experimentation helps advance their cultural citizenship as 'a capacity for action and for responsibility' which 'entails both personal and cognitive dimensions that extend beyond the personal to the wider cultural level of society. (...) [A]s citizenship is an ongoing process that is conducted in communicative links' (Delanty, 2003, p. 602).

Designing for dialogue is key to form these communicative links as several chapters show. They demonstrate what it takes to create 'a dialogic museum' (Tchen, 1992) and transform lofty policy work, which assumes that museums and heritage sites supporting dialogue mark a direct route to intercultural understanding and social harmony (Galani et al., 2020).

As discussed above, both Sørensen, in Chapter 11, and Carter and Lleras, in Chapter 3, show how museum institutions can actively adapt this role as a facilitator of dialogue through the design process. Moreover, Rodanthi Tzanelli, in Chapter 5, documents that a starting point for such dialogues can be museums challenging their established focus on tradition-authenticity-learning. Such a 
challenge affords new relational and reflexive narratives about humans and their (non-human) cohabitants on planet Earth because it fosters dialogues across generations and across a diversity of diasporic communities on the impact of our current environmental crisis and shared planetary futures. Also, Wescley Xavier, Diana Castro and Vanessa Brulon, in Chapter 7, stress how experimentation involving actual and potential museum audiences can challenge physical, social and mental barriers so as to produce a joint awareness of the world, its structures and oneself as an agent of transformation; and hence constitute local residents as democratic citizens. Finally, as Palmyre Pierroux, Birgitte Sauge and Rolf Steier clearly demonstrate, in Chapter 9, museum exhibition spaces may also be rethought as spaces of joint knowledge production transgressing the boundaries between universities and museums in order to establish a joint research space for deliberative collaboration, design-based methods and exhibition research. The result of such experimental knowledge production is a more precise identification of professional values and objectives in service of the public good which, naturally, is a fundamental precursor of cultural citizenship.

As these examples indicate, promoting dialogue to strengthen cultural citizenship is an ongoing, and often contentious, social process. It may figure as a tool when a museum experiments with new designs, it may be applied as a guideline of narration and as a means of address. Whatever the approach, certain key principles stand out. When museums promote dialogue, it is more than an invitation to voice opinions or concerns. So, museums should frame dialogues as processes of commitment, whether the dialogue partners be audiences communicating with museum staff, audiences experiencing multivocal representations at an exhibition or groups of actual or potential audiences communicating amongst themselves online or on site. Promoting dialogue is also more than individual participation and visible listening. So, museum professionals need to scaffold dialogue as an inclusive social practice. Such scaffolding must mediate between institutional authority and audience authority, thus avoiding the pitfalls of assuming that professionals know what is right and pretending that audiences know what is best. Finally, the outcome of dialogue need not be consensus, it may be a shared acknowledgement of difference. Since cultural citizenship is a key resource in democratic societies, it must also share one of its fundamental tenets: to agree to disagree. So, museums have a responsibility to make room for difference in substance as well as form. There is not one right way of arguing or expressing oneself and not one correct solution or outcome. This responsibility is particularly important, because dialogue as a tool of democracy is often focussed on rational argumentation on public issues.

Taken together, the implications of experimental museology are of fundamental importance for the future of museums as dynamic and relevant resources and pillars of public value. This importance stems from the perspective of experimental museology: it moves museums beyond having conversations about change in terms its what, who and why and unto questions of how change may be practised and pursued so as to transform traditions of audience exclusion, of collusion with past colonialism and limited relevance to the majority of people's lives. 
An understanding of museum experimentation as a diverse set of practices that are enmeshed with wider processes of value and power implies that museums cannot limit experimentation to discrete and short-term 'projects' in a particular domain. An experimental museology does not limit itself to experiments within the exhibition halls, on the management floor or in outreach activities. As this volume testifies, an experimental museology entails self-reflexive professional strategies. Such strategies allow for sustained exploration that embraces failures while making sure that particular experiments are systematically monitored and evaluated and that practices and outcomes are understood as part of wider societal contexts of use.

\section{Bibliography}

Dahlgren, P. (2006). Doing citizenship: The cultural origins of civic agency in the public sphere. European Journal of Cultural Studies, 9(3), 267-286.

Delanty, G. (2003). Citizenship as a learning process: Disciplinary citizenship versus cultural citizenship. International Journal of Lifelong Education, 22(6), 597-605.

Galani, A., Markham, K., \& Mason R. (2020). Problematising digital and dialogic heritage practices in Europe: Tensions and opportunities. In A. Galani, K. Markham, \& G. Arrigoni (Eds.), European heritage, dialogue and digital practices (pp. 9-36). Routledge.

Granovetter, M. (1983). The strength of weak ties: A network theory revisited. Sociological Theory, 1, 201-233.

Isin, E. F., \& Nielsen, G. (2002). Acts of citizenship. Zed Books.

Marstine, J. (2011). The contingent nature of the new museum ethics. In J. Marstine (Ed.), The Routledge companion to museum ethics: Redefining ethics for the twenty-first-century museum (pp. 3-25). Routledge.

Miller, T., Birch, M., Mauthner, M., \& Jessop, J., (Eds.). (2012). Ethics in qualitative research (2nd ed.). SAGE.

Pruulmann-Vengerfeldt, P., \& zu Hörste, H. M. (2020). Reimagining audiences in the age of datafication. In M. Filimowicz \& V. Tzankova, V. (Eds.), Reimagining communication: Experience (vol. 2, pp. 179-195). Routledge.

Rasmussen, L. M., \& Cooper, C. (2019). Citizen science ethics [Special issue]. Citizen Science: Theory and Practice, 4(1), 1-3.

Tchen, J. K. W. (1992). Creating a dialogic museum: The Chinatown history museum experiment. In I. Karp, C. M. Kreamer, \& S. D. Lavine (Eds.), Museums and communities: The politics of public culture (pp. 285-326). Washington, DC: Smithsonian Institution Press. 